\title{
doispontos:
}

\section{Filosofia e Historia Natural em Bacon'}

\author{
Luiz Eva \\ Professor de Filosofia do Centro de Ciências Naturais e Humanas (CCNH) da Universidade Federal do ABC \\ (UFABC), São Bernardo, SP, Brasil \\ lalveseva@gmail.com
}

\begin{abstract}
Resumo: Este artigo examina a concepção de História Natural de Francis Bacon a partir de sua relação com literatura cética discutida no século XVI. Mais exatamente, procura mostrar que essa obra representa uma radicalização de uma tendência naturalista presente no tratamento cético da noção de "milagre", tal como reconhecível no De Divinatione, de Cícero, e nos Ensaios de Montaigne, dentre outras obras.
\end{abstract}

Palavras-chave: História Natural, Francis Bacon, ceticismo, milagre, natureza, Montaigne.

\section{Philosophy and Natural History in Bacon}

Abstract: This paper examines the conception of Natural History of Francis Bacon, considered in its relation with the sceptical literature discussed along the XVIth century. More precisely, it maintains that this work can be read as pushing forward a naturalist tendency already present in the sceptical treatment of the notion of miracle, recognizable in works like Cicero's De Divinatione and Montaigne's Essays, among others.

Key-words: Natural History; Francis Bacon; scepticism; miracle; nature; Montaigne.

Nos últimos anos mais atenção se tem dado à relação entre o pensamento de Francis Bacon e o ceticismo filosófico, principalmente a partir dos trabalhos de Charles Schmitt e Richard Popkin sobre a retomada do ceticismo no Renascimento ${ }^{2}$. Bacon não pode, é claro, ser considerado um cético, muito ao contrário. Ao pretender fundar a construção de um edifício de conhecimentos sobre a natureza até então inalcançados pelo homem, ele explicitou sua intenção de superar o diagnóstico de nossa condição humana de ignorância da verdade proveniente dos céticos. Mas isso não significa que ele não tenha se apercebido de muitas similaridades entre sua maneira de ver e a desses filósofos. Ele afirma, no seu Novum Organum (1620), que seu método segue incialmente uma via paralela à dos "que seguiram a tese da acatalepsia" (seguramente uma alusão aos céticos acadêmicos, que defenderam nossa incapacidade de apreender a verdade), pois, no estado atual das coisas, pouco se pode saber ${ }^{3}$. De fato, Bacon inicia seu percurso metódico através de uma exibição da precariedade do saber atual, a assim chamada pars destruens do Novum Organum, na qual se encontra a célebre "doutrina dos ídolos". Embora tampouco se possa considerar tal doutrina como cética, ela claramente se apropria de diversos elementos provenientes dessa tradição filosófica ${ }^{4}$. Superar essa situação de ignorância da natureza, a seu ver, envolveria examinar suas causas e desenvolver um método de investigação alternativo que, em lugar de nos atrelar indefinidamente a esse diagnóstico, fomentasse uma 
esperança razoável de atingir a verdade (cf. N.O., I, \$ 67), como um autêntico conhecimento das formas naturais, ao cabo do trabalho de muitas gerações (do qual ele se pretendia mero iniciador).

Segundo Bacon, a fonte única a partir da qual se pode razoavelmente esperar conhecimento da natureza é a experiência sensível. Por oposição ao modo como Descartes, por exemplo, ao se apropriar metodicamente da dúvida cética, busca validar diretamente nossa capacidade humana de conhecer, Bacon entende que o intelecto humano deixado a si mesmo está inapelavelmente condenado a enredar-se em suas próprias fantasias:

[... De fato, para aqueles cujo propósito seja, não fazer conjecturas e adivinhações, mas descobrir e conhecer, e que não têm em mente compor macaquices e fábulas de mundos imaginários, mas sim olhar dentro da natureza deste mundo verdadeiro e como que dissecá-la, para estes tudo deve ser procurado nas próprias coisas. E para esse trabalho $[\ldots]$ não há substituto ou compensação suficiente com o talento, a meditação ou a argumentação, nem que se unissem todos os talentos de todas as pessoas [...] (BACON, 2015, p. 40).

Para Bacon, então, torna-se preciso metodicamente neutralizar os ídolos de diversas espécies para avançar na direção da observação "dentro da natureza". Como se daria esse processo? O primeiro passo previsto no seu projeto, imediatamente subsequente à elaboração do método (que envolve uma parte destrutiva, uma parte preparativa e uma parte construtiva, onde se esboçam os princípios da verdadeira indução), é a elaboração de uma nova história natural. Nos seus Preparativos para uma História Natural (Parasceve) ${ }^{5}$, um texto de instruções gerais para a realização dessa tarefa publicado conjuntamente com o Novum Organum, ele retoma a mesma ideia apresentada na passagem que acabamos de citar, esclarecendo o seu papel:

[... Também aqui é fundamental repetir o que eu sempre digo: nem mesmo se todos os engenhos humanos de todas as épocas tivessem se associado ou venham a se associar, nem mesmo se todo o gênero humano tivesse se dado ou viesse a se dar ao trabalho da filosofia, e em toda a órbita terrestre nada tivesse havido ou viesse a haver se não academias, colégios e escolas de homens doutos; nem assim se teria podido nem se pode fazer qualquer progresso digno do gênero humano na filosofia ou nas ciências sem uma História Natural e Experimental tal como a que agora iniciamos. Ao contrário disso, porém, uma História desse tipo, comparada e bem instruída, acrescida de experimentos auxiliares e lucíferos, que se oferecerão ou serão buscados no próprio curso da investigação, há de ser obra de poucos anos para a investigação de natureza e de todas as ciências. Desse modo, ou bem se faz o que é preciso, ou se abandona o empreendimento. Tal é, pois, o único e exclusivo modo pelo qual se podem estabelecer os fundamentos de uma filosofia verdadeira e ativa; e os homens assim verão, como que despertos de um profundo sono, a distância que há entre as máximas e ficções dos engenhos e a filosofia verdadeira e ativa, bem como o que vem a ser consultar a própria natureza acerca da natureza [...] (Parasceve, p. 394).

Enquanto o conhecimento das formas naturais (que corresponderiam aos elementos últimos a partir dos quais se pode compreender sua operação), previsto como a culminação do método, decorreria apenas do trabalho cooperativo de muitas gerações, essa nova espécie de história natural é aqui apresentada como trabalho para poucos anos. Sua execução parece ter ganhado importância crescente para Bacon: embora ele pretendesse inicialmente apenas deixar essas diretrizes indicadas para que outros pudessem levar a tarefa adiante (enquanto se dedicaria sobretudo a aperfeiçoar o aparato do método da Indução, exposto de modo apenas preliminar na segunda parte do Organum), ele próprio acabou assumindo as rédeas desse empreendimento. Assim, de uma lista de 150 títulos de histórias particulares publicada com o Parasceve, ele mesmo selecionou seis, que pretendia finalizar como modelos, das quais efetivamente publicou apenas duas - Historia Ventorum (1622) e Historia Vitae Mortis (1623) - e deixou rascunhos de outras (coligidos por G. Rawley em 1626). Embora, até mais recentemente, a exegese baconiana tenha dado importância maior ao exame do seu método da indução do que de sua História Natural (que acabou, todavia, servindo de paradigma às investigações subsequentes da Royal Society, por parte de Boyle, Sydenham e outros) sublinhemos, porém, que, no Aviso ao Leitor que acompanha a publicação da sua História dos Ventos, ele mesmo afirmou o seguinte: enquanto o seu Organum dificilmente seria utilizável por alguém que não 
dispusesse uma "História Natural da espécie adequada", essa própria História Natural, por sua vez, poderia, por si só, ainda produzir algo de sólido, mesmo que acompanhada do velho método aristotélico ${ }^{6}$.

Sendo assim, tendo em mente que a História Natural é parte de um projeto geral de superação da acatalepsia dos céticos, parece-nos relevante examinar se sua concepção exibiria aspectos próprios pelos quais se possam reconhecer, seja certo reconhecimento teórico dos problemas de ordem "cética" a que acabamos de nos referir, seja indícios de como ele pretenderia, através dessa tarefa, deles se distanciar ou mesmo superá-los. Permitiriam esses problemas compreender alguma particularidade da dimensão estratégica dessa tarefa na obtenção de conhecimento? Essa questão ganha talvez maior sentido se observamos que, segundo certa tradição interpretativa de Bacon (Lisa Jardine, em particular), haveria um abismo intransponível entre, de um lado, os objetivos especulativos baconianos referentes à obtenção de conhecimento em si das coisas e, de outro, o estatuto meramente provisório e probabilístico das explicações obtidas no âmbito da História Natural (e mesmo da atividade experimental preconizada na segunda parte do Organum). Tais explicações, no entender dessa comentadora, seriam compatíveis com o probabilismo do Ceticismo Acadêmico ${ }^{7}$ Poderia isso corresponder ao estatuto do conhecimento da natureza que ele pretenderia obter nessa etapa de seu empreendimento? Por outro lado, Bacon enfatiza a novidade de sua História Natural, orientada por uma concepção metódica em que residiria, precisamente, seu eventual valor para a produção de uma nova ciência da natureza. Que alcance teriam essas prescrições diante de suas observações sobre os limites de nosso conhecimento?

Sem pretender aqui oferecer um exame completo desse ponto, destacaremos aqui apenas alguns elementos que nos parece que podem contribuir para sua abordagem. De uma parte, pretendemos mostrar que a História Natural baconiana deve ser compreendida, ao menos em parte, como um resultado indireto do desenvolvimento de uma tradição filosófica naturalista que se moldou com a ajuda de fontes céticas acadêmicas difundidas ao longo do século XVI, particularmente o De Divinatione de Cícero. Mas exatamente, a História Natural de Bacon parece representar uma radicalização da perspectiva, central para autores como Plínio e Cícero, segundo a qual os diversos eventos que se podem oferecer como objeto de uma história - inclusive os fenômenos aparentemente milagrosos - são parte de uma ordem natural a ser investigada e descoberta ${ }^{8}$. Por outro lado, parece-nos que o elemento de sua concepção de História que o próprio Bacon veria como mais relevante para avançar no conhecimento das causas seria, como veremos, o que ele denomina ser a sua dimensão "ativa", e que seguramente se situa, a seu ver, para além do que podem oferecer as Histórias até então disponíveis.

A constituição da História Natural como uma disciplina científica - voltada à coleção e descrição de espécimes naturais de modo sistemático - é um fenômeno próprio do Renascimento, resultante da recepção de fontes antigas (como Aristóteles, Teofrasto, Galeno e Plínio - autor este do qual provém essa expressão). Deu-se primeiramente na Itália e, subsequentemente, propagou-se pelos países nos quais o humanismo italiano adentrou. Brian Olgivie estudou, por exemplo, a evolução do interesse dos humanistas de Ferrara (em torno ao médico e professor de filosofia moral Niccolò Leoniceno), a partir de 1480, pelas obras concernentes à medicina e botânica, buscando inicialmente elucidar contradições entre as fontes, corrigir os textos corrompidos e aprimorar, por meio delas, as práticas médicas'. Posteriormente, retornando aos seus países de origem, no norte da Europa, entre 1530 e 1560, os estudantes do professor Leoniceno se depararam com uma flora diversa, que os conduziu a um trabalho descritivo autônomo, realizado em comunidades de pesquisas na Basiléia, nos Habsburgos e em Bordeaux. Nas três décadas seguintes, seus programas de pesquisa foram elaborados em grau de detalhamento cada vez maior, com o auxílio de coleções 
de outros herboristas e de um modo cada vez menos vinculado às questões práticas sobre o uso das ervas, até o momento em que, ao final do século, o acúmulo dos registros existentes conduziu ao tratamento de problemas específicos de taxonomia e classificação desse material.

No processo examinado por Olgivie, o foco de interesse principal parece ter sido originalmente a obra de Galeno. Mas outros interesses intelectuais humanistas paralelos e relevantes a esse processo se deram no mesmo período. Nas faculdades de Direito de Pádua, Bolonha e Veneza, parecem ter tido maior preponderância o estudo da História Natural de Plínio e de diálogos filosóficos de Cícero. Mas, neste caso, o contato com esses autores antigos esteve menos conectado ao processo de constituição dessa disciplina nova do que a discussões teóricas relevantes para a sua prática, em torno, por exemplo, à concepção de natureza e sua relação com a noção de milagre. Segundo Henri Busson, a História Natural de Plínio teve ao menos 38 edições entre 1469 e 1532 e foi venerada pelos humanistas do início do século XVI como uma espécie de enciclopédia. Nela, múltiplas descrições de casos raros e prodigiosos são apresentadas com o propósito de apoiar a crença de que os supostos milagres deveriam ser sempre compreendidos como resultantes de causas apenas naturais ${ }^{10}$. No segundo livro da obra, Plínio apresenta sua concepção religiosa de um Deus identificado a um mundo imenso e eterno, cujo poder se confunde com o da própria natureza; tal Deus, pensa ele, não faz coisas absurdas (como alterar a ordem dos fatos ou as verdades matemáticas), mas é o responsável por tudo o que ocorre, mesmo o que reputamos ser, à primeira vista, estranho. Ainda segundo Busson, foi particularmente o livro sétimo - no qual Plínio condena a crença na imortalidade e na ressureição, tratando-as como "fábulas para crianças" - que suscitou particular interesse nos debates do período, bem como sua reputação de autor ateu e perigoso.

Essa concepção de Plínio sobre o estatuto dos eventos prodigiosos é similar, ademais, à que encontramos em uma das obras de Cícero particularmente lidas e citadas nesse mesmo período, o diálogo Sobre a adivinhação (De Divinatione $)^{11}$. Nessa obra, encontramos a mesma tese sobre a negação da existência de milagres em um sentido sobrenatural, isto é, entendidos como resultado de uma intervenção particular da providência divina na ordem da natureza. Comentando acerca do relato de casos prodigiosos, Cícero afirma:

Seremos afinal aterrorizados se nos reportam o nascimento de criaturas monstruosas nos animais ou nos homens? Só há, na minha opinião, uma explicação para esses fenômenos. Tudo o que ocorre é resultado de uma causa natural e o que parece estar fora das leis ordinárias nunca pode estar fora da natureza. Encontrai, se podeis, a causa do que vos espanta e surpreende; mas se ela vos escapa, não tendes como menos certo que nada se produz sem uma causa natural $[\ldots]$ (CÍCERO, De Div., II, 28) ${ }^{12}$.

Com base nesse princípio, Cícero conclui que todos os supostos relatos sobre eventos extraordinários devem ser reconsiderados, seja como relatos de eventos possíveis porém naturais, mesmo que raros; seja como relatos fantasiosos de eventos impossíveis (como parece ser o caso das hipóteses supostamente naturalistas que seu interlocutor estóico produz para tentar justificar as supostas faculdades divinatórias dos moribundos e dos oráculos).

Mas haveria alguma relação mais clara entre esta posição defendida por Cícero e o ceticismo? Como ocorre nos Academica ou no De Natura Deorum, também no De Divinatione Cícero defende abertamente a posição da Nova Academia. Depois de apresentar, ao início do diálogo, uma rápida história das crenças sobre a existência das artes divinatórias (acolhidas e sustentadas, diz ele, por diversos filósofos, Sócrates, Pitágoras, a antiga Academia e a maioria dos estóicos), ele explica que lidará com o problema através do mesmo método acadêmico de examinar detalhadamente os argumentos por ambos os lados da questão (in utramque partem). Isso porque, conhecendo as disputas "agudas e copiosas" que Carnéades conduziu sobre o tema, pretende evitar dar o seu assentimento a algo falso ou insuficientemente provado. Nos assuntos 
religiosos, explica Cícero, é preciso evitar a aceitação precipitada das "superstições das velhotas" sem todavia negligenciar o valor devido aos ritos e às religiões, sob o risco de cometer impiedade (cf. De Div., I, 7).

E, efetivamente, a argumentação crítica por ele desenvolvida ao tratar do problema, o conduzirá, por fim, à conclusão de que a crença na adivinhação deveria ter suas raízes extirpadas como um mero produto da superstição (superstitio), que oprime os espíritos apoderando-se da fraqueza dos homens (cf. De Div., II, 148). Isso não significa abandonar, diz Cícero, os ritos e cerimônias ancestrais da religião nem desprezar a beleza da regularidade dos fenômenos celestes; ao contrário, é preciso propagar a religião "que é ligada ao conhecimento da natureza”. Mas Cícero entende que seu juízo próprio sobre a questão é o mesmo que teria sido legado por Carnéades:

[...] pois se Carnéades não tivesse se erguido contra o poder ilimitado [dos filósofos que defenderam a crença na adivinhação através dos encadeamentos lógicos dos sonhos] talvez esses hoje fossem considerados como os únicos filósofos. Quase todos os meus esforços de refutação se dirigem contra eles: não porque eu particularmente os despreze, mas porque eles defendem sua opinião de modo sutil e perspicaz. Mas, como a especificidade da Academia consiste em nunca fazer intervir o seu próprio juízo, a aprovar o que parece mais verossímil, a comparar as causas entre si e expor o que pode ser dito a favor e contra cada opinião, a permitir que os ouvintes guardem a plena liberdade do seu juízo, sem intervir com sua autoridade própria, nós guardaremos esse uso, transmitido por Sócrates, e o adotaremos o mais frequentemente (De Div. II, 150).

Herni Busson indica que essa discussão cética peculiar, que a nós pode hoje parecer lateral ou incomum ao pensarmos nessa corrente filosófica, possuiu um impacto considerável nos debates filosóficos do século XVI. Pedro Pomponazzi é mais conhecido por advogar posiç̃̃es aristotélicas em outros de seus textos hoje menos esquecidos como o Tratado sobre a Imortalidade da Alma (1516), no qual avança considerações que o tornaram conhecido como o propositor de uma doutrina da "Dupla Verdade" (segundo a qual poderiam ser igualmente aceitas, mesmo sendo contraditórias, as verdades filosóficas e teológicas acerca desse tema). Todavia, no seu De Incantationibus (publicado apenas postumamente, em 1556), ele retoma a posição naturalista de Cícero e Plínio sobre o tema dos milagres (referindo-se aliás expressamente a esses autores) e a ela procura adicionar explicações novas, referentes às forças desconhecidas existentes na natureza, no próprio homem e na imaginação humana. Segundo Pomponazzi, as plantas, as pedras e os minerais, alguns dos quais são empregados na medicina, agem sobre o homem, alguns em virtude de propriedades conhecidas e experimentadas, outros, como o magneto, através de virtudes ocultas. Algumas dessas propriedades são reportadas por Alberto Magno, em seu Tratado dos Minerais, ou em Plínio, mas outras são igualmente usadas pelos mágicos:

Conhecendo $[\ldots]$ as plantas dotadas dessas propriedades ocultas, eles as empregam e delas extraem efeitos que parecem aos ignorantes serem vindos de Deus, dos anjos ou de demônios, e que fazem com que seus autores passem como sendo íntimos de espíritos sobrenaturais (POMPONAZZI, De incantationibus, IV, p. 42, apud BUSSON, 1971, p. 57).

Pomponazzi conclui essa discussão avaliando que " [... ] tais teorias derrubam a lei de Moisés e do Cristo, pois estas religiões apóiam sua autoridade e têm seu fundamento mais seguro nos milagres; mas, segundo estas explicações, não há milagres" (POMPONAZZI, De incantationibus, IV, pp. 65-67, apud BUSSON, 1971, p. 59).

Tais concepções adentraram, como também atesta Busson com farta documentação, nos debates filosóficos franceses do século XVI, por intermédio dos diversos humanistas que tiveram, direta ou indiretamente, contato com a escola de Pádua, conduzindo, não surpreendentemente, a muitas controvérsias e acusações de impiedade. Seus ecos seriam claramente reconhecíveis, por exemplo, na definição de milagre formulada pelo humanista Dolet ${ }^{13}$, mas também nas paródias dos milagres bíblicos feitas por Rabelais e Bonaventura 
des Périers; nas teses de Vicomercato, aristotélico de inspiração averroísta que foi professor da cátedra de filosofia do Collège de France, ou nas explicações naturalistas que Cardano pretendeu oferecer em defesa do fenômeno do profetismo, no De rerum varietate (1557). Em 1597, o jesuíta L. Richeome publica o primeiro dos seus Trois discours pour la religion catholique, acerca dos milagres, onde ele retoma a definição de milagre oferecida pelo De Divinatione - "a admiração resultante da inspeção de uma coisa manifesta da qual a causa é desconhecida" - procurando limitá-la ao que ele qualifica como "milagre natural", por oposição aos que seriam os "milagres de Deus", que assim se evidenciariam por se situarem além do curso comum das forças da natureza. Como nota Busson ${ }^{14}$, essa estratégia é pouco promissora e os argumentos de Richeome acabam por ter mais o efeito inverso de aproximar as narrativas de milagres bíblicos aos exemplos tomados de Plínio.

Um último autor que pretendemos aqui mencionar antes de voltar a Bacon é Montaigne, em cujos Ensaios $(1580)^{15}$ se faz enfaticamente presente essa mesma concepção naturalizadora do milagre proveniente de Cícero e Plínio. É bem verdade que Montaigne tem o cuidado de situar fora do debate a sacralidade da religião cristã tal como consignada nas Escrituras (cuidado que, compreensivelmente, ocorre com frequência nos debates do período) e admitir a possibilidade, ao menos em tese, de uma intervenção miraculosa de Deus para além da ordem natural. Mas, no detalhe, o seu tratamento do tema corresponde a uma atitude de dúvida acerca de nossa capacidade de efetivamente conhecer qual é a ordem natural, que o conduz a considerar os casos supostamente extraordinários como parte dessa ordem antes do que como eventos sobrenaturais (pois este é um juízo cuja autoridade nos escapa). Assim, seguindo os passos do $D e$ Divinatione, ele aconselha abertamente, no capítulo Sobre os coxos, que os relatos de bruxaria sejam tomados como resultados, ou bem da fantasia humana, que devem ser contrastada com aquilo que tomamos como verossímil segundo nosso conhecimento da natureza (cf. Les Essais, III, 11), ou bem da deformação de nossa concepção de natureza, derivada apenas de nossa própria ignorância. Diz ele, no capítulo intitulado Apologia de Raymond Sebond, que o que chamamos de natureza é sempre decorrente de nossa própria apreensão relativa e limitada:

\footnotetext{
[...] Quantas coisas não há em nosso conhecimento que se opõem a essas belas regras que nós tecemos e prescrevemos à natureza? [...] Quantas coisas chamamos de milagrosas e contra a natureza? Isso se faz para cada homem e cada nação segundo a medida de nossa ignorância [... ]. Pois ir segundo a natureza, para nós, é apenas ir segundo o nosso entendimento, o tanto que ele pode avançar e o tanto que vemos: o que está além é monstruoso e desordenado (Les Essais, II, 12, 526AC).
}

Essas ideias de Montaigne podem ser tributárias da mesma corrente intelectual naturalista que proveio de Pomponazzi, mas ele também frequentou diretamente as mesmas fontes céticas acadêmicas, bem como as reflexões pirrônicas de Sexto Empírico, criticamente direcionadas ao ceticismo acadêmico, que lhe deram a ocasião de extrair precisões epistemológicas adicionais sobre o estatuto de nosso conhecimento da natureza. No capítulo I, 27, por exemplo, ele assinala que nem mesmo a noção de "verossimilhança" é capaz de nos oferecer um juízo confiável sobre o que a ordem natural ${ }^{16}$. Uma razão é que normalmente interferem na nossa apreensão da natureza outras instâncias, como o costume, cujo principal efeito é o de esconder-se a si mesmo, diz ele, na medida em que as coisas por ele produzidas nos aparecem como "naturais": "[...] Os milagres existem segundo a ignorância em que nos encontramos da natureza, não segundo o ser da natureza. O acostumar-se adormece a vista de nosso juízo [... ]" (Les Essais, I, 23, 112A).

Montaigne também cita com frequência a História Natural de Plínio, que lhe fornece, como Plutarco, exemplos acerca da variedade natural dos comportamentos humanos e animais. Não há nos Ensaios nada que se aproxime de um projeto sistemático de empreender uma História Natural. Mas não percamos de vista que o seu propósito, através de seus diversos exemplos, é geralmente o de exibir a elástica variedade 
da natureza ou da cultura e, através daí, a precariedade da imagem da natureza de que dispomos, mesmo daquela que seria a nossa própria, posto que está sempre impregnada dos nossos próprios costumes. Sobre a diversidade de comportamentos animais, por exemplo, ele escreve:

\begin{abstract}
Nós admiramos e valorizamos mais as coisas novas do que as comuns, e sem isso eu não teria me ocupado deste longo registro (de comportamentos animais); pois, na minha opinião, quem acompanhar de perto o que vemos comumente sobre os animais que vivem entre nós, encontrará ações tão admiráveis quanto essas que recolhemos nos países e séculos estrangeiros. [...] É uma mesma natureza que segue o seu curso. Quem tiver julgado de modo capaz o presente estado, terá dele concluído todo o futuro e todo o passado. (Les Essais, II, 12, 467A).
\end{abstract}

Assim, ainda que Montaigne critique constantemente a pretensão das filosofias de obter uma imagem coerente da natureza humana, dada a diversidade, a mutabilidade e a natureza contraditória dos comportamentos humanos, essa passagem mostra que seu ceticismo se conjuga perfeitamente com uma crença na existência de uma natureza que opera por leis regulares, mesmo que as desconheçamos, em detrimento das crenças fantasiosas na ocorrência de eventos sobrenaturais, os quais efetivamente não podemos detectar por não dispormos de critérios para tanto.

Bacon vislumbrou, como vimos, na realização de uma nova História Natural, o passo inicial de um empreendimento de reformulação dos saberes. Mas em que sentido ela deve ser propriamente "nova", a seu ver? Bacon sustenta que o ponto central dessa novidade, do qual os outros devem derivar, concerne à sua finalidade: trata-se de buscar, através dela, não o deleite intelectual, mas o conhecimento da verdade. Mais exatamente, seu objetivo é " [...] reunir e comparar uma grande quantidade e variedade de coisas que bastem para a confecção dos axiomas verdadeiros [...]” (Parasceve, \$ II, p. 396). Para além de questões concernentes à massa de registros ou aos critérios de sua elaboração ${ }^{17}$, podemos reconhecer que sua recusa do apelo causado pela narrativa de fatos aparentemente insólitos é também acompanhada pela observação de que o costume é, ao menos em parte, responsável pelo recorte particular com que a natureza se apresenta a nós - tal como ocorre no caso de Montaigne. Embora o costume seja incluído de modo relativamente discreto entre os chamados "ídolos da Caverna" (os impedimentos ao conhecimento dependentes de nossas diferenças individuais) (cf. N.O., I, $\$ 53$ ), Bacon assinala que "na [sua] opinião, o maior obstáculo à filosofia provém de que as coisas familiares e comuns não detêm o exame dos homens, mas são consideradas de passagem, sem que se interrogue sobre suas causas" (N.O., I, $\mathbb{1} 119$ ). Ademais, Bacon entende que a investigação da natureza não deve ser guiada por nenhum juízo prévio sobre aqueles que seriam os valores intrínsecos à natureza dos objetos (como parecia fazer a filosofia aristotélica), pois as coisas "baixas e vulgares" devem ser historiadas tanto quanto as que julgamos preciosas ${ }^{18}$.

Sugerimos, acima, que Bacon não apenas segue a mesma tradição naturalista que remonta a Plínio e Cícero na elaboração de sua História Natural, mas que a radicaliza. Dizemos isso em vista de suas considerações sobre a novidade do acervo de sua História, isto é, da espécie de objetos que ela inclui e, consequentemente, do escopo da noção de natureza que ela pretende abarcar (cf. N.O., I, \$ 98). Nos Preparativos, Bacon divide a História Natural em três partes: a "História das Gerações" (i.e., das coisas tal como a natureza espontaneamente os apresenta), a "História das Contragerações" (i.e., dos "monstros", das aparentes exceções ao que parece ser, em princípio, natural) e a "História das Artes". Segundo Bacon, essas partes teriam razão de ser por corresponderem a três aspectos da própria natureza:

A Natureza se dispõe em um tríplice estado e se submete, por assim dizer, a um regime trino. Pois ela, ou está livre e decorre segundo o seu curso ordinário, ou é expulsa do seu estado pelas deformidades e enormidades da matéria e pela violência dos obstáculos, ou bem é presa e modelada pela arte e pelo asserviçamento (ministerio) humanos. E o 
primeiro desses estados corresponde às espécies das coisas, o segundo aos monstros, o terceiro às coisas artificiais. Pois, nas coisas artificiais, a natureza sofre o jugo do império humano, posto que nunca teriam sido produzidas se não pelo homem. Mas pela obra e ministério dos homens observa-se um aspecto dos corpos inteiramente novo e, por assim dizer, um outro universo de coisas, ou um outro âmbito de representações (Parasceve, \$ I, p. 395).

No entender de Bacon, o escopo temático da espécie de história natural até então empreendida corresponderia a apenas uma das cinco subdivisões da primeira parte, a "história das gerações", por ele denominada de "coleções menores (ou de espécies)" (Parasceve, \$ IV, p. 398). Para além desta, porém, o seu leque temático deve se abrir, a seu ver, para o registro do que ocorre na região do éter, dos meteoros e das coisas celestes, da terra e do mar, bem como dos "elementos" (na medida em que apreensíveis pela experiência), dos comportamentos humanos, das percepções específicas, dos produtos culturais, e diversos outros tópicos. Mais relevante para o nosso ponto, contudo, é o fato de que o âmbito em que se há de buscar o reconhecimento de leis naturais passa agora a abarcar, para além daquilo que a natureza espontaneamente oferece, tanto os prodígios quanto os artefatos produzidos pelo homem. Assim, além de notar que frequentemente será mais oportuno considerar a História das Gerações e das Contragerações conjuntamente (i.e., do que ocorre segundo sua ordem espontânea e de seus desvios, aqui compreendidos os "milagres"), Bacon afirma que as "histórias das artes" são as que se revelariam mais úteis para o conhecimento da natureza, uma vez que esta se exibe principalmente quando é "apertada e perturbada", isto é, retirada do seu estado comum pelo trabalho e arte humanos (cf. N.O., I, \$98). Além disso, como já notamos, é um aspecto explícito da concepção baconiana de História Natural o fato de ela possuir uma dimensão ativa. Não se trata apenas de descrever os eventos como apresentados pela natureza no seu curso ordinário, mas também incluir na própria atividade de historiar a realização de experimentos. Bacon tem em mente um gênero determinado de experimentos, que ele denomina de "lucíferos", destinados a corroborar ou afastar hipóteses sobre as causas de eventos particulares, por oposição aos experimentos "frutíferos", que seriam aqueles diretamente voltados à obtenção de resultados práticos19. Esses experimentos lucíferos são, na verdade, um prolongamento deliberadamente planejado do resultado cognitivo espontaneamente obtido pelas artes humanas.

E o que pensa Bacon sobre os milagres no sentido estrito do termo, como ocorrências para além da ordem natural? Ao menos nos Preparativos, deparamo-nos com uma única referência enigmática ao assunto, por meio da qual ele efetivamente distingue as Contragerações dos Milagres propriamente ditos:

Quanto ao que cabe à História das Contragerações, eu disse mais acima que ela pode vantajosamente ser conjugada com a História das Gerações. Refiro-me, é claro, apenas às coisas que são prodigiosas e naturais. Pois a História Profética (superstitiosam) dos Milagres (e do que seja desse gênero) relegamos inteiramente a um tratado próprio. E esta não deve ter seu princípio erigido agora, mas um pouco depois, quando mais longe tivermos penetrado na investigação da natureza (Parasceve, \$ IV, p. 398) ${ }^{20}$.

Sejam o que forem os milagres que caberiam nessa História Profética, a passagem é clara ao assinalar que eles podem futuramente ter nela lugar, mas sempre como objeto de uma explicação naturalista. Assim, por mais que Bacon possa preservar um espaço próprio para o milagre em sentido estrito, o seu projeto filosófico circunscreve, ao menos em tese, o espaço de uma ciência da natureza voltada à busca de causas mesmos diante de todos os eventos em princípio disponíveis que poderiam supostamente se pretender subtrair da ordem natural.

Alguns comentários buscam sublinhar aspectos pelos quais a filosofia de Bacon seria subsidiária da teologia e nota-se efetivamente a presença constante de referências teológicas ao longo de suas considerações. Mas, ainda que Bacon busque efetivamente conciliar aspectos de seu projeto a crenças religiosas (a começar pela ideia fundamental de que estaria disponível aos homens uma Restauração de seus direitos originais de 
conhecimento das coisas, por meio de uma alusão explícita à doutrina cristã da Queda), quão longe devem essas reflexões, afinal, nos levar da concepção ciceroniana de uma religiosidade manifesta na observação da ordem natural e "que é ligada ao conhecimento da natureza" - por oposição à crença supersticiosa nos milagres?

Concluiremos com uma palavra sobre o estatuto das regularidades que Bacon espera conhecer através do esforço empreendido pela História Natural. Corresponderiam eles ao conhecimento das verdades últimas sobre a natureza que visa o seu projeto? Uma passagem particularmente interessante se encontra na segunda parte do Novum Organum, onde, tratando da "história das gerações", Bacon afirma que ela inclui tanto o estudo dos corpos como os encontramos no "curso ordinário da natureza", quanto "os hábitos particulares e especiais da natureza, por oposição às leis fundamentais e comuns que estabelecem as formas" (N.O., II, $\mathbb{S}$ 5; grifo nosso). Talvez seja um problema efetivamente insolúvel saber como é possível passar da observação dos "hábitos naturais", ordinários ou especiais, às leis próprias das formas em si, a que ele almeja como o coroamento do seu método, mas não é por acaso que essa é a mesma terminologia retida, nesse mesmo sentido, pelos empiristas modernos - Locke, por exemplo - ao pretenderem diferenciar nosso conhecimento "nominal" das substâncias naturais, tal como se oferece pela experiência disponível, da sua essência real ${ }^{21}$.

\section{NOTAS}

1. Versões anteriores deste texto foram apresentadas no colóquio "Natureza, Artefatos e a Filosofia Moderna", organizado por Ronei Mocellin, na UFPR, em julho de 2016; no colóquio "Filosofia, literatura e política no pensamento moderno", organizado por Danilo Marcondes, na PUC-RJ, em novembro de 2016, e no Seminário de Pesquisa da UFABC, organizado por Luciana Zaterka, em agosto de 2017.

2. Ver POPKIN (2000), SCHMITT (1972). Sobre Bacon e o ceticismo, ver, dentre outros, JARDINE (1985), GRANADA (2006), EVA (2008), EVA (2011), OLIVEIRA e MAIA NETO (2009), MANZO (2009), SMITH (2015). Popkin, ele próprio, faz apenas alusões muito passageiras a Bacon.

3. Cf. Novum Organum (doravante N.O.), I, \37. In: BACON (1889), vol. I.

4. É o que procurei mostrar e discutir em EVA (2008) e (2011).

5. In: BACON (1889), vol. I; doravante Parasceve.

6. Cf. SPEDDING, J. “Preface” ao Parasceve. In: BACON (1889), vol. I, p. 384.

7.JARDINE (1985), pp. 138-143, 151-152.

8. Observemos aqui, de passagem, que a compreensão da dimensão "cética" desse pressuposto requer a consideração de fontes acadêmicas ciceronianas que não são consideradas por Popkin. Dado que Popkin se limita ao exame das fontes pirrônicas, é importante considerar que essa lacuna pode ser eventualmente fonte de uma distorção quando estamos preocupados em obter uma imagem mais abrangente da presença do ceticismo na filosofia do século XVI.

9. OLGIVIE (2006), p. 29 ss.

10. BUSSON (1971), p. 37, cf. ainda pp. 37-43.

11. CÍCERO (2004), De Divinatione; doravante De Div.

12. Cf. BUSSON (1971), p. 37. 
13. "Milagre é tudo o que é de natureza a provocar nossa surpresa. Se os cristãos aplicam [o termo] hoje apenas ao que é digno de admiração, os antigos o aplicavam ao que é feio, pois para eles os milagres eram os monstros e as coisas horríveis", apud BUSSON (1971), p. 115.

\section{Ver BUSSON (1971), pp. 450-452.}

\section{Cf. MONTAIGNE (1988), doravante Les Essais.}

16. "Se dizemos ser monstro ou milagre aquilo que nossa razão não alcança, quanto disso não se apresenta continuamente aos nossos olhos [... É É preciso julgar com mais reverência essa infinita potência da natureza e com maior reconhecimento da nossa ignorância e fraqueza. Quanto não há de coisas pouco verossímeis, testemunhadas por pessoas dignas de fé, das quais, se não podemos ser persuadidos, ao menos é preciso deixá-las em suspenso. Pois condená-las como impossíveis é se fazer capaz, por uma temerária presunção, de saber até onde vai a possibilidade [... ]", Les Essais, I, 27, 179A.

17. Segundo Bacon, a história existente é "leviana e pobre”, posto que a observação é feita de modo indiligente e fortuito, a tradição dos conhecimentos naturais é "vã e formada de rumores” e os experimentos são "cegos, estúpidos, vagos e interrompidos", BACON, 2015, p. 40. Em contrapartida, ele mesmo delineia sua novidade não apenas em vista dos seus fins e tarefas, mas também quanto ao acervo a ser coletado, à sutileza dos experimentos e dos objetos a serem buscados e à disposição material para a tarefa subsequente.

18. “( ... ) a história natural não se sujará com isso, pois o sol penetra as cloacas, como os palácios, sem nunca se sujar [... ]”, N.O., I, \$ 120; cf. Parasceve, \$ VI, p. 400.

19. Segundo Bacon, “a esperança em um progresso ulterior das ciências será bem fundada quando na História Natural se reunir e recolher uma massa de experimentos que por si mesmo não são de nenhuma utilidade, mas que se prestam apenas à descoberta das causas e dos axiomas”, N.O., I, $\$ 99$. Os experimentos lucíferos, destinados a esse fim, são aqueles que por sua natureza "nunca enganam": "Com efeito, como seu emprego não visa produzir uma obra, mas indicar uma causa natural de algo, pouco importa o resultado: respondem igualmente ao objetivo buscado, pondo um termo à questão", N.O., I, $\$ 99$. Noutras palavras, eles permitiram, ou bem a constatação de que a presumida causa permanece acompanhando o efeito (eventualmente demandando novas investigações), ou bem a recusa de uma falsa causa.

20. O termo superstitio tem entre seus significados igualmente "objeto de temor religioso" (sentido em que foi empregado noutra passagem acima pelo autor), "objeto de adesão escrupulosa” ou "objeto de reverência".

21. Este termo reaparecerá com o mesmo sentido, por exemplo, na obra de Locke, e por razões aparentemente análogas, cf. Ensaio sobre o Entendimento Humano, Livro IV, Capítulo iii, \$ 29.

\section{REFERÊNCIAS}

BACON, F. 1889. The Works of Francis Bacon in VII volumes. Ed. by J. Spedding, R. L. Ellis, and D. D. Heath. London: Longman \& Co. et al.

2015. A grande restauração - Textos introdutórios e A escada do entendimento. Trad. e apresentação de Alessandro Rolim de Moura e Luiz A. A. Eva. Curitiba: Segesta Editora.

BUSSON, H. 1971. Le Rationalisme dans la littérature française de la Renaissance 1533-1601. Second tirage. Paris: Vrin. 
CICERO. 2004. De la Divination (De Divinatione). Présentation et trad. de José Kany-Turpin. Paris: GF-Flammarion.

EVA, L. 2008. Francis Bacon: ceticismo e doutrina dos ídolos. Cadernos de História e Filosofia da Ciência, Campinas, Série 3, vol. 18, nº 1, jan.-jun., pp. 47-84.

2011. Bacon's 'Doctrine of the Idols' and Skepticism. In: MACHUCA, D. (ed.). Pyrrhonism in Ancient, Modern and Contemporary Philosophy. Dodrecht: Springer, pp. 99-129.

GRANADA, M. A. 2006. Bacon and scepticism. Nouvelles de la République des Lettres, nº II, pp. 91-105.

JARDINE, L. 1985. Experientia Litterata ou Novum Organum? Le dilemme de la méthode scientifique de Bacon. In: MALHERBE, M.; POUSSEUR J.-M. (orgs.). Francis Bacon, Science et Méthode. Paris: Vrin, pp. 135-157.

MANZO, S. 2009. Probability, Certainty and Facts in Francis Bacon's Natural History. A Double Attitude towards Skepticism. In: MAIA NETO, J. R.; PAGANINI, G.; LAURSEN, J.-C. (eds.). Skepticism in the Modern Age: Building on the Work of Richard Popkin. Leiden, Boston: Brill, pp. 123-137.

MONTAIGNE, M. de. 1988. Les Essais. Paris: P.U.F.

OLGIVIE, B. W. 2006. The Science of Describing: Natural History in Renaissance Europe. Chicago, London: The University of Chicago Press.

OLIVEIRA, B. J.; MAIA NETO, J. R. 2009. The sceptical evaluation of techné and baconian science. In: PAGANINI, G.; MAIA NETO, J. R. (eds.). Renaissance Scepticisms. Netherlands: Springer, pp. 249-273.

POPKIN, R. 2000. A História do Ceticismo de Erasmo a Espinosa. Tradução de Danilo Marcondes. Rio de Janeiro: Francisco Alves.

SCHMIT, C. B. 1972. Cicero Scepticus: A Study of the Influence of the Academica in the Renaissance. The Hague: Martinus Nijhoff.

SMITH, P. 2015. Por que Bacon pensa que o ataque cético ao dogmatismo é insuficiente?. In: $O$ método cético de oposição na Filosofia Moderna. São Paulo: Alameda Editorial, pp. 75-105. 